\title{
POTENCIAL ANTIFÚNGICO DE ÓLEO ESSENCIAL EXTRAÍDOS DE FOLHAS DE ARAÇÁ (Psidium guineense Sw.) CONTRA Sporothrix Sp.
}

M. T. E. VAZ ${ }^{1}$, W. K. COSTA ${ }^{1}$, J. W. L. M. SILVA' ${ }^{2}$, C. A. T. VALERIANO ${ }^{3}$, J. V. O. ALVES ${ }^{1}$, V. B. G. SILVA ${ }^{1}$, V. E. P. GUIMARÃES ${ }^{1}$, B. O. VERAS ${ }^{1}$, A. G. SILVA ${ }^{1}$ e M. V. da SILVA ${ }^{1}$.

- Universidade Federal de Pernambuco, Centro de Biociências, Departamento de Bioquímica ${ }^{2}$ Instituto Aggeu Magalhães, Fiocruz - Pernambuco

${ }^{3}$ Universidade Federal de Pernambuco, Centro de Biociências, Departamento de Micologia

E-mail para contato:tereza_vazz@hotmail.com

RESUMO - A esporotricose trata-se de uma infecção causada pelo fungo do gênero Sporothrix. Manifesta-se comumente sob a forma cutâneo-linfática. Sua via de transmissão é através do solo ou por felinos infectados. Esse trabalho avaliou o potencial do óleo essencial do Araçá (Psidium guineense Sw.) como agente antifúngico contra cinco isolados clínicos do gênero Sporothrix sp. As folhas de Araçá foram coletadas no Parque Nacional do Catimbau, e submetidas à técnica de hidrodestilação para extração do óleo essencial. A determinação da concentração inibitória mínima (CIM) seguiu o protocolo M38-A2/CLS, com adaptações. O antifúngico padrão foi o Itraconazol. Para os óleos testados, utilizou-se o óleo bruto. Os isolados de Sporothrix sp. foram mantidos em meio BatataDextroseAgar (BDA) e incubados a $35^{\circ} \mathrm{C} / 7$ dias. As suspensões foram preparadas em solução salina $(0,85 \mathrm{~g} / \mathrm{L})$, e sua densidade ajustada utilizando espectrofotômetro a 530nm, para uma concentração de $2-5 \times 10^{3}$ céls $/ \mathrm{mL}^{-1}$. Foram feitos os semeios e as placas incubadas a $35^{\circ} \mathrm{C} / 72 \mathrm{~h}$. O óleo de Araçá inibiu o crescimento de Sporothrix sp. e Candida parapsilosis ATCC 22019 (Controle positivo) no poço onde ocorreu maior diluição (1:512). Itraconazol apresentou variação de 0,125 a $16 \mu \mathrm{g} / \mathrm{mL}$-1 para Sporothrix sp. e inibiu a ATCC a uma concentração de 0,0625 $\mu \mathrm{g} / \mathrm{mL}^{-1}$. Em conclusão, o óleo essencial de Araçá apresenta atividade anti-esporotricose. $O$ trabalho segue visando a caracterização química e a determinação do princípio ativo do óleo essencial.

Palavras chaves: anti-esporotricose; concentração inibitória mínima; infecção fúngica

ABSTRACT: Sporotrichosis is an infection caused by the fungus of the genus Sporothrix. It is commonly found in the cutaneous-lymphatic form. Its route of transmission is through the soil or through infected felines. This work evaluated the potential of essential oil Araçá (Psidium guineense Sw.) as an antifungal agent against five clinical isolates of the genus Sporothrix sp. Araçá leaves were collected in the Catimbau National Park, and submitted to the hydrodistillation technique to extract the essential oil. The determination of the minimum inhibitory concentration (MIC) followed the M38-A2/CLS protocol, with adaptations. The 
standard antifungal was Itraconazol. For the oils tested, the crude oil was used. The isolates of Sporothrix sp. were maintained in BatataDextroseAgar (BDA) and incubated at $35^{\circ} \mathrm{C} / 7$ days. The suspensions were prepared in saline solution $(0.85$ $\mathrm{g} / \mathrm{L})$, and their density adjusted using spectrophotometer at 530nm, at a concentration of 2-5x103 cells $/ \mathrm{mL}^{-1}$. Sows and plates were incubated at $35^{\circ} \mathrm{C} / 72 \mathrm{~h}$. Araçá oil inhibited the growth of Sporothrix sp. and Candida parapsilosis ATCC 22019 (Positive Control) in the well where the highest dilution occurred (1: 512). Itraconazol presented variation from 0.125 to $16 \mu \mathrm{g} / \mathrm{mL}^{-1}$ for Sporothrix sp. and inhibited ATCC at a concentration of $0.0625 \mu \mathrm{g} / \mathrm{mL}^{-1}$. In conclusion, Araçá's essential oil has anti-sporotrichosis activity. The work continues aiming at the chemical characterization and determination of the active principle of the essential oil.

Keywords: anti-sporotrichosis; minimum inhibitory concentration; fungal infection

\section{INTRODUÇÃO}

A Esporotricose trata-se de uma infecção subaguda ou crônica causada pelo fungo do gênero Sporothrix. A doença manifesta-se mais comumente sob a forma cutâneolinfática, mas também existem as formas: cutânea localizada, cutânea disseminada e extra cutânea. Nos últimos anos essa infecção vem sendo um problema de saúde pública tanto na Região Metropolitana do Recife (RMR) quanto em outros estados brasileiros (MARIMON et al., 2007; SANCHOTENE et al., 2015).

Uma de suas principais vias de transmissão é através do solo, acometendo geralmente pessoas com ocupações ligadas a terra, principalmente em áreas rurais. Porém, nos últimos anos os casos em regiões metropolitanas vêm aumentando significativamente, isso se dá pelo hábito de felinos domésticos escavarem a terra para encobrir fezes, adquirindo assim a infecção fúngica. Os felinos infectados podem transmitir essa infecção para outros animais e até mesmo para humanos, essa transmissão se dá por meio de arranhaduras, mordidas ou até mesmo o contato direto com as lesões (KAUFFMAN et al., 2007).

A Esporotricose pode acometer pessoas de ambos os sexos, de qualquer faixa etária ou raça, independente de fatores individuais predisponentes. Por ser contagiosa e o tratamento ser longo e pouco conhecido, os tutores abandonam os animais acometidos, contribuindo assim para disseminação do patógeno no ambiente e assim havendo aumentado de casos (WALLER et al., 2017)

O tratamento recomendado tanto para seres humanos quanto para animais é o uso do antifúngico Itraconazol, devido a sua eficiência e segurança terapêutica já conhecida. Entretanto, nos últimos anos o surgimento de resistência ao antifúngico recomendado tornou o controle da doença mais difícil (CHAVES et al., 2012; RODRIGUES et al., 2012). Então a busca de novos compostos eficazes no tratamento dessa infecção se faz necessário, principalmente a busca por plantas com potencial medicinal e seus derivados, já que a produção e o tratamento farmacológico de inúmeras patologias tiveram seu início com a utilização de plantas medicinais WALLER et al., 2017).

O Araçá (Psidium guineense SW) é um arbusto pertencente à família Myrtaceae, e possui ampla distribuição no território brasileiro, bem como em outras partes do mundo, podendo alcançar 1,5 metro de altura, com caule de casca lisa, folhas simples e flores brancas axiliares (FERREIRA et al., 2011; SOBRAL et al., 2010). Além de ser utilizada para a produção de frutas, tanto para o consumo in natura quanto para a agroindústria, a 
espécie também vêm despertando a atenção da indústria farmacêutica por sua alta capacidade medicinal contra microrganismos (FRANZON, 2009). Segundo a literatura etnofarmacológica, o Araçá é uma planta que é usada no tratamento caseiro da diarreia, além de ser utilizado no combate a infecções da boca e garganta, e em lavagens locais de úlceras e leucorreia (CAMPOS, 2010).

Diante da necessidade de pesquisar novos compostos com potencial antiesporotricose, esse trabalho avaliou o potencial do óleo essencial do Araçá (Psidium guineense $S w$.) como agente antifúngico contra diferentes isolados clínicos do gênero Sporothrix sp.

\section{MATERIAIS E MÉTODOS}

As folhas frescas de Psidium guineense Sw. foram coletadas no Parque Nacional do Catimbau, localizado no agreste de Pernambuco, numa região de Caatinga. A confirmação da identificação botânica foi realizada pela Dra. Rita de Cássia A. Pereira curadora do Herbário Dárdano de Andrade Lima (IPA), onde um exemplar da espécie foi depositado sob o $n^{\circ}$ 96789. As folhas foram submetidas à técnica de hidrodestilação no Departamento de Bioquímica da Universidade Federal de Pernambuco para extração do óleo essencial. Depois de extraído, o óleo essencial foi armazenado em frasco âmbar e mantido em baixas temperaturas até o momento do uso.

A determinação da concentração inibitória mínima (CIM) foi realizada através da técnica de microdiluição de caldo em placas de 96 poços. Seguiu-se o protocolo M38-A2 (CLSI, 2008), com adaptações. O antifúngico padrão utilizado foi o Itraconazol em concentrações variando de 0,015 a $16 \mu \mathrm{g} / \mathrm{mL}^{-1}$. Para os óleos testados, utilizou-se o extrato bruto e foi feita a diluição seriada até uma proporção de 1:512. Obtendo-se óleo em concentrações de $100 \mu \mathrm{l} / \mathrm{ml}$ até $0,195 \mu \mathrm{l} / \mathrm{ml}$. Essas concentrações foram distribuídas no sentido das colunas das microplacas em volumes de $100 \mu 1$.

Foram obtidos cinco isolados de Sporothrix sp. do laboratório de Micologia Médica e Imunodiagnóstico do Departamento de Micologia da Universidade Federal de Pernambuco. Para o controle positivo foi utilizado a cepa Candida parapsilosis ATCC 22019.

Os isolados de Sporothrix sp. foram mantidos em meio Batata Dextrose Agar (BDA) e incubados a $35^{\circ} \mathrm{C}$ durante 7 dias. As suspensões dos isolados foram preparadas em solução salina $(0,85 \mathrm{~g} / \mathrm{L})$, e sua densidade ajustada de acordo com a escala 0.5 de McFarland em $80 \%$ a $82 \%$ da transmitância utilizando um espectrofotômetro a $530 \mathrm{~nm}$. O volume do inóculo foi posteriormente diluído em RPMI 1640 para uma concentração de $2-5 \times 10^{3}$ céls $/ \mathrm{mL}^{-1}$. Foram utilizadas placas de microtitulação planas de 96 poços (TPP; Trasadingen, Suíça) para os testes. $O$ inóculo foi adicionado aos poços com os antifúngicos e as placas incubadas a $35^{\circ} \mathrm{C}$, durante $72 \mathrm{~h}$, antes de ler os resultados para determinação da CIM frente à droga padrão e aos óleos testados, A CIM foi obtida pela comparação visual do crescimento do agente ocorrido nos poços referentes às diferentes concentrações testadas, com o seu crescimento no controle positivo. E foi considerada CIM a menor concentração capaz de inibir $100 \%$ do crescimento a olho nu.

\section{RESULTADOS E DISCUSSÃO}

A concentração inibitória mínima (CIM) do Itraconazol para os isolados de Sporothrix sp. testados apresentaram uma variação de 0,125 a $16 \mu \mathrm{g} / \mathrm{mL}^{-1}$ e inibiu a Candida parapsilosis ATCC 22019 a uma concentração de $0,0625 \mu \mathrm{g} / \mathrm{mL}^{-1}$, os valores de 
CIM de Itraconazol superiores a $8 \mu \mathrm{g} / \mathrm{mL}^{-1}$ podem estar associados à resistência antifúngica segundo as diretrizes M38-A2 (CLSI, 2008). Já a Concentração inibitória mínima do óleo essencial de Psidium guineense Sw. inibiu o crescimento de Sporothrix sp. no poço onde o volume do óleo era de $0,195 \mu \mathrm{l} / \mathrm{ml}$, sendo o poço onde ocorreu maior diluição (1:512), assim como também inibiu a ATCC 22019 (Candida parapsilosis) no poço onde o volume do óleo era de $0,195 \mu \mathrm{l} / \mathrm{ml}$, também na maior diluição do óleo $(1: 512)$.

Curiosamente, todos as cepas de Sporothrix sp. foram susceptíveis na menor concentração do óleo essencial do Araçá, inclusive as que podem ser consideradas resistentes ao antifúngico Itraconazol.

Esse valor homogêneo observado para os valores de CIM do óleo de Araçá diferente do que se observa para o agente antifúngico onde se obtêm diferentes valores de CIM, provavelmente ocorre pela diversidade de compostos químicos encontrados no óleo essencial do Araçá, que dificulta os microrganismos de desenvolverem mecanismos de resistências, como ocorre com os princípios ativos dos fungicidas (OLIVEIRA et al., 2016).

Mesmo sabendo que o Araçá apresenta atividade anti-esporotricose, ainda não foi possível determinar o mecanismo de ação do óleo. Acredita-se que a ação antimicrobiana possa ser decorrente da alteração de diversas enzimas, incluindo aquelas envolvidas com a produção de energia e a síntese de componentes estruturais. Em geral, o estudo do mecanismo de ação dos óleos essenciais tem usado metodologia comum na tentativa de ilustrar os efeitos prejudiciais que ocorrem na membrana celular (WALLER et al., 2017)

\section{CONCLUSÃO}

Folhas de Psidium guineense Sw. são fontes de óleo essencial com atividade antiesporotricose, visto que apresentou um resultado melhor que o antifúngico recomendado. O trabalho segue visando a caracterização química e a determinação do princípio ativo do óleo essencial.

\section{REFERÊNCIAS}

CAMPOS, Letícia Zenóbia de Oliveira. Etnobotânica do Gênero Psidium L. (Myrtaceae) no Cerrado brasileiro. 86 f. Tese (Doutorado) - Curso de Mestrado em Botânica, Pósgraduação em Botânica, Universidade de Brasília, Brasília, 2010. Disponível em: $<$ http://repositorio.unb.br/bitstream/10482/7836/1/2010_LetíciaCampos.pdf $>$. Acesso em: 19 Ago. 2016.

CHAVES, A. R. et al. Treatment Abandonment in Feline Sporotrichosis - Study of 147 Cases. Zoonoses And Public Health, [s.1.], v. 60, n. 2, p.149-153, 17 ago. 2012. Wiley-Blackwell. http://dx.doi.org/10.1111/j.1863-2378.2012.01506.x.

CLSI - Clinical and Laboratory Standards InstituteReference Method for Broth Dilution Antifungal Susceptibility Testing of Filamentous Fungi. M38-a2 Guideline. Approved Standard (third ed.), Wayne, PA, USA (2008).

FERREIRA, Perácio Rafael Bueno et al. Morphoanatomy, Histochemistry and Phytochemistry of Psidium guineense Sw. (Myrtaceae) Leaves. Journal Of Pharmacy, Índia, v. 4, n. 4, p.942-944, abr. 2011. 
FRANZON, Rodrigo Cezar et al. Araçás do gênero Psidium: principais espécies, ocorrência, descrição e usos. Distrito Federal: Embrapa Cerrados 2009. 49 p. Disponível em: $<$ http://bbeletronica.cpac.embrapa.br/2009/doc/doc_266.pdf $>$. Acesso em: 20 Out. 2017.

KAUFFMAN, Carol A. et al. Clinical Practice Guidelines for the Management of Sporotrichosis: 2007 Update by the Infectious Diseases Society of America. Clinical Infectious Diseases, [s.1.], v. 45, n. 10, p.1255-1265, 15 nov. 2007. Oxford University Press (OUP). http://dx.doi.org/10.1086/522765.

MARIMON, R. et al. Sporothrix brasiliensis, S. globosa, and S. mexicana, Three New Sporothrix Species of Clinical Interest. Journal Of Clinical Microbiology, [s.1.], v. 45, n. 10, p.3198-3206, 8 ago. 2007. American Society for Microbiology. http://dx.doi.org/10.1128/jcm.00808-07.

OLIVEIRA, V. M. et al. Quercetin and rutin as potential agents antifungal against Cryptococcus spp. Brazilian Journal Of Biology, [s.1.], v. 76, n. 4, p.1029-1034, dez. 2016. FapUNIFESP (SciELO). http://dx.doi.org/10.1590/1519-6984.07415.

RODRIGUES, Anderson Messias et al. Genetic diversity and antifungal susceptibility profiles in causative agents of sporotrichosis. Bmc Infectious Diseases, [s.1.], v. 14, n. 1, p.219-228, 23 abr. 2014. Springer Nature. http://dx.doi.org/10.1186/1471-2334-14-219.

SANCHOTENE, Karine Ortiz et al. Sporothrix brasiliensisoutbreaks and the rapid emergence of feline sporotrichosis. Mycoses, [s.1.], v. 58, n. 11, p.652-658, 25 set. 2015. WileyBlackwell. http://dx.doi.org/10.1111/myc.12414.

SOBRAL, Marcos et al. Myrtaceae in Lista de espécies da flora do Brasil. Jardim Botânico do Rio de Janeiro. Disponível em: <http://floradobrasil.jbrj.gov.br/jabot/floradobrasil/FB10867>. Acesso em: 19 Out. 2016

WALLER, Stefanie B. et al. Chemical and cytotoxic analyses of brown Brazilian propolis (Apis mellifera) and it's in vitro activity against itraconazole-resistant Sporothrix brasiliensis. Microbial Pathogenesis, [s.1.], v. 105, p.117-121, abr. 2017. Elsevier BV. http://dx.doi.org/10.1016/j.micpath.2017.02.022.

\section{AGRADECIMENTOS}

Agradecemos a CAPES pela concessão da bolsa, ao Departamento de Bioquímica e ao Departamento de Micologia da Universidade Federal de Pernambuco pelo auxílio nos equipamentos necessários para a realização da Pesquisa. 